American Journal of Environmental Sciences 4 (4): 281-284, 2008

ISSN 1553-345X

(C) 2008 Science Publications

\title{
Estimate Polluting Agents
}

\author{
Abdelhani Boukrouche \\ Laboratory of Automatic and Computer L.A.I.G., \\ Department of Electronic Engineering, Faculty of Sciences and Engineering, \\ P.O. Box: 401 Guelma, 24000, Algeria
}

\begin{abstract}
The concentration estimation of hydrocarbons not burned emitted in smokes by a boiler during its beginning will be discussed in the present investigation. The objective is to verify if the boiler is conform to European norms; so that a recorded data processing has been achieved with a restoration method based on the use of two regularization parameters resulting in the combination of optimal filtering and deconvolution. The application of this technique to the available data has permitted to verify the boiler conformity to the new European standards.
\end{abstract}

Key words: Deconvolution, ill-posed problem, optimal filtering, regularization

\section{INTRODUCTION}

The environmental aspect takes an increasingly important place in the political and economic life, which is translated into new requirements in European norms. Thus, the quantity of gaseous pollutants emitted in the atmosphere by boilers of central heating functioning to the gas or to the fuel is submitted to regular thresholds. Industries have been submitted to constraints, which can be satisfied by different manners. It can be decided for example to build up a new process or modify the old one, but this approach risk to be relatively expensive. Otherwise, it is possible to verify whether the measures recorded are reliable. The reliable measures can be seen as the input of a distortion process (the data acquisition device) whose output is the recorded measures corrupted by noise. In such point of view, with the knowledge of the data acquisition device, one can try to restore the reliable measures, compare them to the norm specifications and so make a decision. This technique of signal restoration is a deconvolution.

\section{RESTORATION TECHNIQUE}

Concentrations of polluting gas emitted $\left(\mathrm{CO}_{2}, \mathrm{CO}\right.$, $\mathrm{C}_{\mathrm{n}} \mathrm{H}_{\mathrm{m}}$ and $\mathrm{NO}_{\mathrm{X}}$ ) are measured during of the continuous functioning of the boiler. To the lighting of the burner, gaseous pollutant emissions are during a short moment more raised than in continuous functioning. Relative European norms to fuel burners and on the basis of these boilers lay down thresholds for the hydrocarbons not burned at the beginning, which has to be verified by a measure.

Considering the physics of the chain of measure and due to the fact that the measure is undertaken in transitory regime, the obtained measure signal is deformed and therefore unusable, it is necessary to undertake a processing of the collected information so as to find the original information.

In control theory, the response of a process to an exciting signal is described by the convolution product such as follows:

$$
y(t)=\int_{-\infty}^{+\infty} h(t-\tau) u(\tau) d \tau
$$

Where $h(t)$ is the impulse response of the process and $u(t)$ is the excitation. The inverse operation consisting in the reconstruction of the signal $\mathrm{u}(\mathrm{t})$ knowing $\mathrm{y}(\mathrm{t})$ and $\mathrm{h}(\mathrm{t})$, is called deconvolution. This technique has a wide array of application (such as astronomy, seismology, spectroscopy, etc.) and also a wide range of solutions $s^{[2,3,4,7,9]}$ already existing.

As one may find in the literature, this problem is known to be an ill-posed one.

\section{DESCRIPTION OF THE METHOD}

The convolution procedure is described in the following figure:

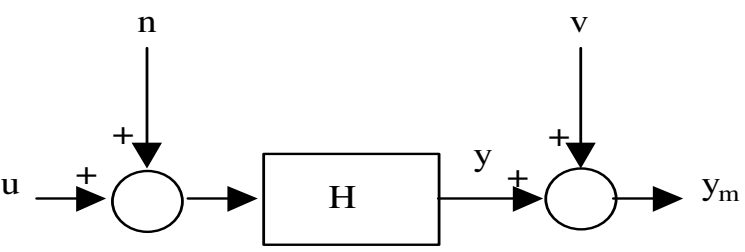

Fig. 1: Block diagram of the signal distortion 
Am. J. Environ. Sci., 4 (4): 281-284, 2008

$\mathrm{u}(\mathrm{t}) \quad=$ input signal

$\mathrm{y}_{\mathrm{m}}(\mathrm{t})=$ recorded signal

$\mathrm{n}(\mathrm{t})=$ gaussian noise added in the input of a variance $\sigma_{1}$

$\mathrm{v}(\mathrm{t})=$ gaussian noise added in the output of a variance $\sigma_{2}$

$H(s)=$ The Laplace transform of $h(t)$, where $h(t)$ is the impulse response

In the following, $\mathrm{h}$ is supposed to be known as in ${ }^{[6]}$. Deconvolution consists to estimate the original object from $y_{m}$ and various known informations about the system of measurement.

Now we propose to give a brief description of the procedure: We have

$$
y_{m}(t)=y(t)+v(t)
$$

with

$$
\mathrm{y}(\mathrm{t})=\mathrm{h}(\mathrm{t}) *[\mathrm{u}(\mathrm{t})+\mathrm{n}(\mathrm{t})]
$$

Where * represents the convolution operator and $\mathrm{h}$ is the Inverse Fourier Transform of $\mathrm{H}$.

We propose to determine ${ }^{[5]}$ an optimal estimation $\hat{y}$ of $y$ such that $\mathrm{E}\left\{(\hat{\mathrm{y}}-\mathrm{y})^{2}\right\}$ is minimum, $\mathrm{E}\{\ldots\}$ is the average operator.With

$$
\hat{y}=f(t) * y_{m}(t)+g(t) * u(t)
$$

We show that

$$
\left\{\begin{array}{l}
F(w)=\frac{|H(w)|^{2}}{|H(w)|^{2}+\frac{\gamma_{v}}{\gamma_{n}}} \\
G(w)=H(w)(1-F(w))
\end{array}\right.
$$

where $\mathrm{F}, \mathrm{G}$ are the filters to be determined, there are the Fourier transforms of $\mathrm{f}$ and $\mathrm{g}$.

$\gamma_{\mathrm{n}}$ and $\gamma_{\mathrm{v}}$ are spectral densities of signals $\mathrm{n}$ and $\mathrm{v}$, respectively.

Eq. (1) becomes

$$
\hat{\mathrm{y}}=\mathrm{f} *\left[\mathrm{y}_{\mathrm{m}}-\mathrm{h} * \mathrm{u}\right]+\mathrm{h} * \mathrm{u}
$$

Now, the problem is to find the optimal value of input signal $u$.
We have

$$
\hat{\mathrm{y}}-\mathrm{h} * \mathrm{u}=\mathrm{f} * \mathrm{y}_{\mathrm{m}}-\mathrm{f} * \mathrm{~h} * \mathrm{u}
$$

$\hat{y}$ being the best estimate of $y$ in term of the mean square error.

We have

$$
\|\hat{\mathrm{y}}-\mathrm{h} * \mathrm{u}\|_{2}^{2} \leq\left\|\mathrm{y}_{\mathrm{m}}-\mathrm{h} * \mathrm{u}\right\|_{2}^{2}
$$

It is possible to find this filter by mean of classical technique based on the calculus of variation, but another proof using known results on Wiener filtering is proposed here by means of variable manipulations. As

$$
\mathrm{y}_{\mathrm{m}}-\mathrm{h} * \mathrm{u}=\mathrm{y}_{\mathrm{m}}-\mathrm{y}+\mathrm{y}-\mathrm{h} * \mathrm{u}=\mathrm{v}+\mathrm{h} * \mathrm{n}
$$

becomes

$$
\|\hat{y}-\mathrm{h} * \mathrm{u}\|_{2}^{2} \leq\|\mathrm{v}+\mathrm{h} * \mathrm{n}\|_{2}^{2}=\varepsilon^{2}
$$

using (4) and (6) we obtain

$$
\left\|\mathrm{f} * \mathrm{y}_{\mathrm{m}}-\mathrm{f} * \mathrm{~h} * \mathrm{u}\right\|_{2}^{2} \leq \varepsilon^{2}
$$

We suggest to determine u such that:

$$
\left\{\begin{array}{l}
\left\|\mathrm{f} * \mathrm{y}_{\mathrm{m}}-\mathrm{f} * \mathrm{~h} * \mathrm{u}\right\|_{2}^{2} \leq \varepsilon^{2} \\
\|\mathrm{u}\|_{2}^{2} \leq \beta^{2}
\end{array}\right.
$$

where $\beta$ is a predefined constant.

This can be obtained by minimization of

$$
\mathrm{J}=\left\|\mathrm{f} * \mathrm{y}_{\mathrm{m}}-\mathrm{f} * \mathrm{~h} * \mathrm{u}\right\|_{2}^{2}+\alpha\|\mathrm{u}\|_{2}^{2}
$$

with

$$
\alpha=\left(\frac{\varepsilon}{\beta}\right)^{2}
$$

The optimal solution $\hat{\mathrm{u}}_{\alpha}$ is given ${ }^{[1]}$ by:

$$
\left(\alpha+(f * h)^{*} *(f * h)\right) * \hat{u}_{\alpha}=(f * h)^{*} * f * y_{m}
$$

$(\mathrm{f} * \mathrm{~h})^{*}$ being the conjugate operator of $(\mathrm{f} * \mathrm{~h})$.

In Fourier space, we write: 


$$
\left(\alpha+(F \cdot H)^{*} \cdot(F \cdot H)\right) \cdot \hat{U}_{\alpha}=(F \cdot H)^{*} \cdot F \cdot Y_{m}
$$

$F, Y_{m}$ and $\hat{U}_{\alpha}$ are the Fourier transforms of $f, y_{m}$ and $\hat{\mathrm{u}}_{\alpha}$ respectively and (F.H) ${ }^{*}$ is the conjugate of (F.H). So we have to obtain a signal $\hat{\mathrm{U}}_{\alpha}$ such as

$$
\mathrm{Y}_{\alpha}=\mathrm{R}_{\alpha} \cdot \hat{\mathrm{U}}_{\alpha}
$$

Where

$$
\mathrm{Y}_{\alpha}=(\mathrm{F} . \mathrm{H})^{*} \cdot \mathrm{F} . \mathrm{Y}_{\mathrm{m}}
$$

and

$$
\mathrm{R}_{\alpha}=\alpha+(\mathrm{F} . \mathrm{H}) * .(\mathrm{F} . \mathrm{H})
$$

The Inverse Fourier Transform of (10) is:

$$
\mathrm{y}_{\alpha}=\mathrm{r}_{\alpha} * \hat{\mathrm{u}}_{\alpha}
$$

$\hat{u}_{\alpha}, y_{\alpha}, r_{\alpha}$ are, respectively the Inverse Fourier transforms of $\hat{U}_{\alpha}, Y_{\alpha}, R_{\alpha}$. The developed method drive to the next configuration.

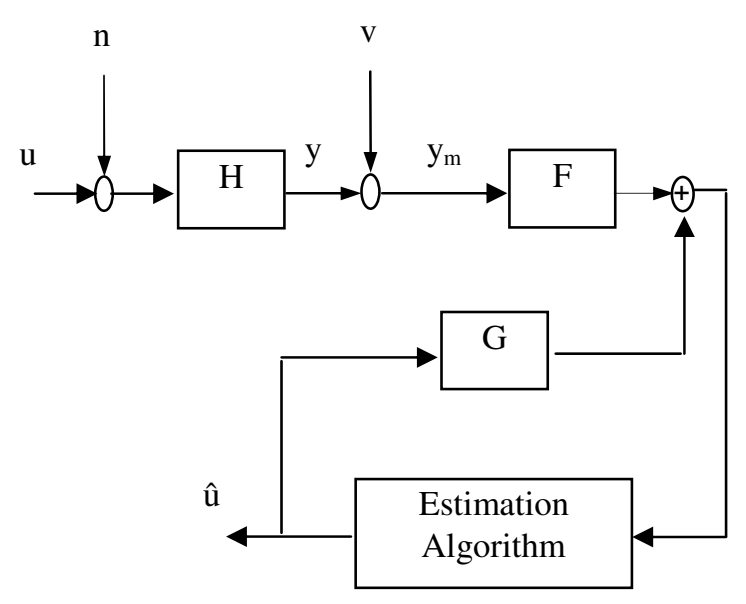

Fig. 2: Interpretation of the proposed technique

\section{APPLICATION}

The proposed method is applied to reconstruct instantaneous concentration of the polluting agents $\left(\mathrm{C}_{\mathrm{n}} \mathrm{H}_{\mathrm{m}}\right)$ emitted by the boiler. The measured signal is distorted by the system of measurement. The aim of the deconvolution is to reduce the distortion effect and so to have access to the instantaneous concentration of the polluting agents. A boiler is qualified to the European Standards of Safety if the instantaneous concentration of $\left(\mathrm{C}_{\mathrm{n}} \mathrm{H}_{\mathrm{m}}\right)$ is inferior to $10 \mathrm{ppm}, 20 \mathrm{sec}$ after his starting.

The constrained iterative method ${ }^{[8]}$ is used to determine $\hat{\mathrm{u}}_{\alpha}$ from (11).

$$
\left\{\begin{array}{l}
\hat{\mathrm{u}}_{\alpha, \beta}=\mathrm{y}_{\alpha} \\
\hat{\mathrm{u}}_{\alpha, \mathrm{k}+1}=\mathrm{p}\left(\hat{\mathrm{u}}_{\alpha, \mathrm{k}}\right)+\lambda\left(\mathrm{y}_{\alpha}-\mathrm{r}_{\alpha} * \mathrm{p}\left(\hat{\mathrm{u}}_{\alpha, \mathrm{k}}\right)\right)
\end{array}\right.
$$

$\mathrm{p}$ is a constrained operator.

$$
\left\{\begin{array}{l}
\mathrm{p}\left(\hat{\mathrm{u}}_{\alpha, \mathrm{k}}\right)=0 \\
\mathrm{p}\left(\hat{\mathrm{u}}_{\alpha, \mathrm{k}}\right)=\hat{\mathrm{u}}_{\alpha, \mathrm{k}} \text { if } \hat{\mathrm{u}}_{\alpha, \mathrm{k}} \succ 0
\end{array}\right.
$$

For our application the system of measurement is modelised by:

$$
\mathrm{H}(\mathrm{s})=\frac{0.1896}{\mathrm{~s}^{3}+1.387 . \mathrm{s}^{2}+0.9852 . \mathrm{s}+0.1901}
$$

We took $\left(\frac{\sigma_{2}}{\sigma_{1}}\right)^{2}=0.5, \alpha=1 . \mathrm{e}^{-7}$ and $\lambda=1.5$

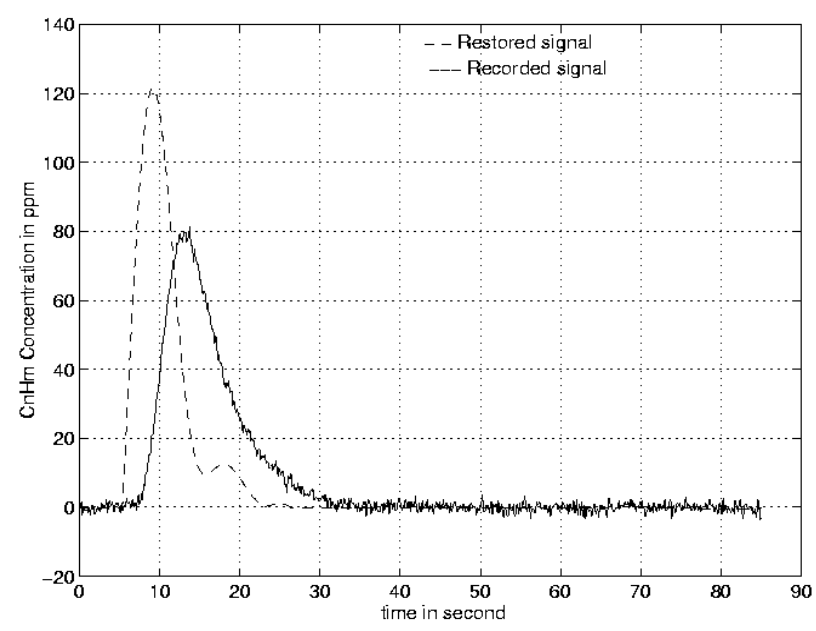

Fig. 3: Restored and recorded signal

According to the European Standards of Safety; Fig. 3 shows that if the recorded signal (full line) is used the boiler would be disqualified; on the other hand the restored signal (dotted line) permits to qualify the boiler. 


\section{CONCLUSION}

Most deconvolution procedures are split in two steps: a filtering used to remove the measurement noise from the recorded signal and afterwards a deconvolution technique developed in a deterministic frame. In this work we suggest a deconvolution procedure which includes the filtering step.

In the described approach, we included an optimal filtering step in the deconvolution algorithm which consists in reducing the distortion effect caused by the measure process on the recorded signal. The problem of the instantaneous hydrocarbon concentration $\left(\mathrm{C}_{\mathrm{n}} \mathrm{H}_{\mathrm{m}}\right)$ estimation, emitted by a boiler, has been approached through the signal reconstruction aspect in order to qualify the boiler to the European Standards of Safety. The $\left(\mathrm{C}_{\mathrm{n}} \mathrm{H}_{\mathrm{m}}\right)$ estimation has been done through the elaboration of an approach of deconvolution.

The proposed technique has been carried on $\mathrm{C}_{\mathrm{n}} \mathrm{H}_{\mathrm{m}}$, however it can be applied to many other polluting agents.

\section{REFERENCES}

1. Badeva, V. and V. Morozov, 1991. Problèmes Incorrectement Posés. Théorie et Applications, Ed. MASSON.

2. Engl, H.W., M. Hanke and A. Neubauer, 1996. Contrained Iterative Restoration Algorithms, Regularization of Inverse Problems. Kluwer Academic publ., Dordrecht.
3. Engl, H.W., M. Hanke and A. Neubauer, 1996. Regularization of Inverse Problems (Dordrecht: Kluwer).

4. Janson, P.A., 1984. Deconvolution with Application to Spectroscopy, New York Academic.

5. Kalman, R.E., 1960. A New Approach to Linear Filtering and Prediction. J. Basic Eng., pp: 35-40.

6. Katsagellos, A.K., et al., 1991. A Regularized Iterative Image Restoration Algorithm, IEEE Trans. Signal Process, 39: 35-40.

7. Prost, R. and R. Goutte, 1984. Discrete Constrained Iterative Deconvolution Algorithms with Optimized Rate if Convergence. Signal Processing, 7: 209-230.

8. Schafer, W., R.M. Mercereau and M.A. Richards, 1981. Constrained Iterative Restoration Algorithms. Proceeding IEEE, 69: 432-450.

9. Sekko, E., A. Boukrouche, G. Thomas and P. Sarri, 1997. Comparaison de deux méthodes de restauration d'images : Application à l'astronomie. Seizième Colloque GRETSI, Grenoble, pp: 837839. 